\title{
LA GLOBALIZACIÓN Y LOS CÍRCULOS CONCÉNTRICOS DE INTEGRACIÓN EN EL NUEVO ORDEN ECONÓMICO MUNDIAL
}

\author{
Máximo Ugarte Vega Centeno
}

mugartev@yahoo.com

\begin{abstract}
RESUMEN
No solo Europa está avanzando en la creación de un mercado único en su territorio, que es un eslabón más en una importante tendencia mundial hacia la agrupación de países con intereses comerciales comunes; también los países de América Latina están tratando de difundir sus intereses comunes en el seno de entidades que les permitan participar con un mayor peso en la economía mundial. Un futuro de bloques económicos interdependiente está a la vuelta de la esquina.
\end{abstract}

Palabras clave: Globalización e integración.

\section{ABSTRACT}

Not only Europe is making progress in creating a single market in its territory, it's just another link in a major global trend towards grouping of countries with common commercial interests; the countries of Latin America are trying to spread their common interests within organizations to enable them to participate with greater weight in the world economy. A future of interdependent economic blocs is just around the corner.

Keywords: Globalization and integration.

* Diplomado en Gestión por el Programa de Alta Dirección (PAD), Universidad de Piura; Magister por la Universidad de Barcelona (España) y Doctor en Estudios Internacionales por la Universidad de Córdoba (España). Profesor Principal de la Universidad Nacional Mayor de San Marcos 


\section{INTRODUCCIÓN}

El paradigma de la globalización y los procesos de integración ha estado marcado por diferentes cambios a través de la historia económica y, a su vez, ha conseguido diferentes formas de organización y desarrollo. En este nuevo contexto muchos afirman, de un lado, que la modernidad y la democracia vienen a ser binomios inseparables y, por otro lado, que la integración regional es el mecanismo más adecuado para acelerar el desarrollo económico-comercial de los países en mercados internos, que les permitiría integrarse con competitividad en la actual globalización de la economía y el comercio mundial.

En la actualidad, se plantea una agenda internacional bastante extensa en la mayoría de los procesos de integración; nosotros orientaremos el estudio a los procesos más influyentes, a nuestro criterio, principalmente la experiencia de la Unión Europea y América Latina por ser de interés por las características y experiencia en el proceso de construcción.

Podemos decir que los orígenes de la integración entre Europa y América del sur son distintos. El primero surge a mediados de los años 50; su conformación original no comprendía la cantidad de países miembros que hoy en día tiene la Comunidad Europea. Su origen se vincula a las consecuencias de la Segunda Guerra Mundial, en los aspectos económicas y sociales que dejaron en la mente de generaciones la marca de la guerra y de la destrucción, y surge también como una forma de hacer frente ante los dos bloques que dominaban la escena internacional (Estados Unidos y la Unión Soviética). En cambio, la integración en América Latina se origina la integración de sus estructuras y sistemas económicos para no ser marginados del mercado internacional, y en la búsqueda de un mejor posicionamiento en el mundo.

La integración en un mercado común permite beneficiarse de las ventajas comparativas y derivadas a los países miembros, tales como acceso a las materias primas, mayor diversidad de productos puesto a los consumidores, mayor competencia, por lo tanto, mayor calidad de los bienes y servicios ofrecidos a menor precio, reducción de costos aduaneros, transporte y comunicación por la apertura e integración física de los estados que constituyen esta alianza; contexto en el que surgen nuevos procesos y se profundiza la integración de diversos países.

En los países de América Latina está en vigencia el comercio mundial para esta década, y su oportunidad dependerá del fortalecimiento y dinámica de los espacios económicos regionales actuales: Asociación Latinoamericana de Integración (ALADI), Mercado Común Centro Americano (MCCA), Mercado Común del Cono Sur (MERCOSUR), y Comunidad Andina (CA). Los países latinoamericanos, en este marco económico, comercial y jurídico, tienen que alcanzar mayores escalas productivas, asociándose cada vez más a estos procesos de integración.

\section{ANTECEDENTES}

Toda organización o institución es el resultado de una serie de hechos que expresan, a la vez, las aspiraciones, preocupaciones o convicciones de aquellos que contribuyeron a su constitución. América Latina no es una excepción. En estos últimos años, la tendencia de integración en la economía mundial globalizada es un aspecto importante a resaltar, por la reaparición y el interés de integrar las economías nacionales en agrupaciones que se distingan por tener zonas de libre cambio, unión aduanera, mercado común, unión económica y unión política ${ }^{1}$, siguiendo la orientación en materia económica internacional y en las relaciones del comercio internacional en los años siguientes a la Segunda Guerra Mundial, cuando se recibió la influencia de uniones aduaneras y de la escuela neo funcionalista, que concebían el proceso de integración en una forma gradual y progresiva. En cuanto a las características principales de todo proceso de integración regional, se han establecido algunos criterios a tomar en consideración, como: los sujetos son los Estados soberanos; los estados emprenden el proceso integrador en forma voluntaria y deliberada; todo

1 Al respecto, en materia económica internacional y relaciones internacionales en los años siguientes a la Segunda Guerra Mundial véanse, Meade, J. (1995). The theory of Customes Unions. Ámsterdam: North Holland Publishing Co.; Has, E. (1964). Beyond The Nations State: Funcionalism and International Organiztion. Palo Alto, California: Stanford University; Balassa, B. (1961). The Theory of Economic Integration. Homewood, Illions, Richard D. Irwin, Inc.; Casado Raigón, J.M. (1992). "La integración económica europea”. En: La integración europea en la perspectiva del 92. I Curso de Comunidades Europeas, Colección Arco de Europa, Córdoba. Sobre la expansión de espacios económicos, véase también "La aceleración del proceso del desarrollo. Las políticas nacionales e internacionales y los problemas económicos en el decenio de 1990”. En: Informe del Secretario General de la UNCTAD a la VII UNCTAD. 09 de agosto de 1991, pp. 8-10. TD/354. 
proceso debe avanzar por etapas que cada vez deben ser más profundas y dispersas, en otras palabras, debe ser gradual, de allí la necesidad de la progresividad y la convergencia del proceso; y el proceso de integración se inicia con acercamientos económicos, pero lentamente y dependiendo de cada proceso -conforme a lo estipulado por los estados miembros-, la agenda va abarcando e incluyendo nuevos temas de la áreas sociales, culturales, jurídicas y hasta política de los países miembros $^{2}$.

Desde el punto de vista del derecho económico internacional, los Estados que se agrupan, ya sea en organizaciones de vocación universal (susceptibles de asociar a todos los Estados) o en organizaciones de vocación regional (que asocian a Estados de una región o continente), pasan a ser nuevos sujetos de derecho internacional y están dotados de personalidad jurídica. En efecto, el profesor Peláez Marón indica que es el proceso seguido por un conjunto de Estados independientes que comparten determinados factores comunes y, precisamente a partir de los mismos, pretenden aprovechar sus complementariedades para un beneficio colectivo. Esto se traduce en el establecimiento de un esquema organizativo jurídico-internacional que comporta unas instituciones dotadas de determinadas competencias ${ }^{3}$.

Como consecuencia de estos procesos de integración jurídico-económica en el ámbito regional, han tenido lugar, en todos los continentes y también en el latinoamericano, cambios que pueden ser significativos en el sistema comercial y/o en las relaciones internacionales ${ }^{4}$.

En ese orden de ideas nos planteamos la siguiente hipótesis:

\section{HIPÓTESIS}

El nuevo orden internacional de la economía mundial trae como consecuencia un nuevo marco jurídico en las relaciones de integración económica y política, en los países desarrollados y en desarrollo, como en América Latina

\section{ANÁLISIS Y DISCUSIÓN}

Por las características del estudio descriptivo tomaremos en consideración los siguientes indicadores de la hipótesis planteada:

1. El nuevo orden económico internacional

2. El nuevo marco jurídico de integración de los países desarrollados.

3. El nuevo marco jurídico de integración económica en los países en desarrollo de América Latina.

\section{El Nuevo Orden Económico Internacional}

Hoy, todos los entendidos en estudios internacionales coinciden en aseverar que nos encontramos ante un escenario mundial distinto al que se generó después de la Segunda Guerra Mundial y después de la caída del muro de Berlín en 1989, y muchos indican que los países desarrollados amenazados de colapsar por la crisis financiera internacional -superior a la crisis asiática de 1997- han puesto en cuestión los principios del libre mercado y de la no intervención del Estado (el rescate de los bancos y de los banqueros irresponsables por parte de los gobiernos con dinero de los contribuyentes).

En esa orientación podemos señalar que la actual coyuntura de esta realidad global o de globalización tiene como protagonista a la crisis internacional financiera que viene generando preocupación entre los agentes económicos, organizaciones empresariales y organizaciones internacionales, así como en los gobiernos debido a la interconexión de los mercados que reflejan cambios en los flujos financieros y comerciales, en la tecnología de la información y en las comunicaciones, en la movilidad de la mano de obra, en la interconectividad internacional y en las nuevas fuerzas de la competencia, que han acelerado la inminente recesión económica en todos los países que traería como consecuencia el decrecimiento del PBI mundial al 4.5\% el 2012.

2 Ver Mariño, Jorge. (1999). La Supranacionalidad en los procesos de integración regional. España, Editor Mave; ver Pérez, Rogelio. (1997). Historia de la política de la unión Europea, 1940-1995. España, Editorial Dykinson.

3 Véase, Peláez Marón, J.M. (1992). "Las relaciones de la Comunidad Europea-América Latina y la búsqueda del interlocutor adecuado". En: Cuestiones actuales de derecho comunitario europeo". Córdoba, Editorial Tipografía Católica, p. 227. Véanse también: Peláez Gonzáles, M. (1984). "Otras organizaciones internacionales en América”. En: Instituciones de Derecho Internacional Público (M. Diez de Velasco). Cuarta Edición. Tomo II. Madrid, editorial, pp. 390-423; Carraud, M. (1980). L'intégration des pays andins. Editorial Paría; Álvarez García, M. (1979). L'integration Latinoamericaine. Bruselas; Díaz Muller, L. (1979). "La integración de América Latina: Un desafío permanente". México, ETM, 3, pp.503-540.

4 Al respecto véanse Barbé, Esther. (1995). Relaciones Internacionales. España, Editorial Tecnos; Deutsch, Karl. (1990). Análisis de las relaciones internacionales. Argentina, Editorial Paidós; Dougherty, James. (1993). Teorías en pugna en las relaciones internacionales. Argentina, Grupo Editor Latinoamericano. 
Ante la actual situación internacional el presidente de Estados Unidos, Barack Obama, reconoció que la culpa de la crisis económica la tienen los bancos por haber asumido riesgos exorbitantes con la compra de títulos de calidad dudosa con el dinero de otros. La crisis se va extendiendo a otras latitudes como la Eurozona que necesita un sistema que resuelva el tema de los bancos, y últimamente se lanzan nuevos salvavidas económicos para seguir inyectando a las decaídas economías de los países mediterráneos (Grecia, España, Portugal, Italia) pensando que estos paquetes marquen el principio del fin de la crisis internacional.

Ante este panorama internacional surgen interrogantes como por ejemplo: ¿Dónde están los nuevos paradigmas que nos servían de punto de referencia en la integración y en las relaciones económicas internacionales? ¿Estados Unidos y la Unión Europea siguen representando un paradigma? Antes de la crisis, Estados Unidos se presentaba con un crecimiento sostenido, baja inflación, baja tasa de desempleo, alto consumo, perspectivas de superávit en las finanzas públicas. Por su lado, la Unión Europea tenía como carta de presentación a la integración, su Estado de bienestar, su democracia madura, sus instituciones fortalecidas, modelos de redistribución económica e instrumentos para la cohesión social, modelos que siempre estuvieron presentes en Latinoamérica, caracterizada por la mala distribución de su riqueza y que vive bajo el apremio del sistema internacional, mientras que sus sistemas nacionales se han visto afectados por las demandas sociales que vienen generando conflictos sociales, que pueden debilitar sus débiles instituciones y derivar en inestabilidad e ingobernabilidad. El desencuentro entre sociedad y el Estado está, todavía, vigente.

La crisis se extiende con pronósticos reservados, lleva más de cuatro años y medio y es considerada la más larga luego de la postguerra, si bien por debajo de la crisis de 1929. De la bipolaridad vamos camino a la multipolaridad. La globalización desigual tendría que ser cambiada, como indica Samir Amin, por una globalización multipolar regulada, donde los bloques o uniones económicas y políticas regionales en África, Asia, América Latina, El Caribe y Medio Oriente sean los protagonistas para la reestructuración global de la economía internacional en la que las zonas de influencia se pone en cuestión y van surgiendo alianzas y nuevos liderazgos comerciales de los países denominados emergentes como Brasil, Rusia, India, China, y Sudáfrica ante los ejes tradicionales de dominación (Estados Unidos, Unión Europea y Japón) con sus respectivas zonas de influencia. La actual tendencia progresista de los gobiernos en América Latina podría ayudar a mejorar sustantivamente la integración regional sustentada en el comercio justo y la democratización, la inclusión social y el desarrollo económico y social, preservando el concepto de sustentabilidad o de sosteniblemente que no degrade los ecosistemas bajo ningún tipo de explotación de malas prácticas y manejos medioambientales.

Ante el escepticismo de muchos, nosotros sostenemos, de una parte, que seguimos creyendo que la integración regional en América Latina -con sus propios problemas o sin ellos (el gasto armamentista crece y muchas veces se priorizan los acuerdos bilaterales)- es una necesidad para una mejor inserción en el mercado globalizado y, por ahora, una de las mejores formas de obtener beneficios y posicionamiento en la economía y el comercio internacional es negociar en bloque ante las economías dominantes de las potencias comerciales ${ }^{5}$. La profundización de los acuerdos comerciales, como la Comunidad Andina de Naciones (CAN) o Mercosur, es una responsabilidad de los países miembros que necesitan mayores relaciones económicas y comerciales.

El cambio de siglo ha traído nuevas exigencias en la economía y el comercio internacional, la tecnología e incluso en el uso del Internet, que son las que han acentuado la divulgación de los conocimientos y el incremento del rol social de las empresas en el avance de las organizaciones, así como su creciente papel en las sociedades.

Por eso, hoy afirmamos que el cambio global en el mundo nos hace observar y pensar de una manera distinta y que necesitamos nueva formas de entender los conceptos de identidad, nación, interés nacional, nacionalidad, Estado, mercado, comercio internacional, los Derechos Humanos, la educación y el medio ambiente.

De otra parte, Estados Unidos ha demostrado seguir siendo la mayor potencia económica y militar del planeta, pese a la crisis internacional,

5 Al respecto véase, Ugarte Vega Centeno, Máximo Alfredo. (1994). "Hacia un Nuevo orden económico mundial”. En: Cuadernos Jurídicos. $\mathrm{N}^{\circ} 15$. Barcelona, editorial Fontalba S.A., pp.42 y ss. 
y diríamos que su liderazgo se ha fortalecido más por lo mismo que ninguna otra potencia ha podido asumir o llenar el vacío que existió en un determinado momento. China todavía no subirá a ese pedestal y, en la actualidad, se va configurando un multilateralismo lento y de baja intensidad.

\section{El Nuevo Marco Jurídico de Integración de los Países Desarrollados.}

La idea de establecer una "unión de integración", sea a través de actos bélicos o a través de acciones pacíficas, no es una invención de nuestro siglo. Para comprender las integraciones es necesario siempre recurrir a sus bases históricas, jurídicas y políticas en las que se fundamenta una organización; en otras palabras, una comunidad se construye con la contribución de distintos componentes como la historia, la cultura, el arte, la religión, la economía y con el ordenamiento jurídico en un estado de derecho y de ahí surgen los pensamientos jurídicos en cada país para poder integrarse. Ese contexto tomaremos como punto de referencia de integración de los países desarrollados: la Unión Europea, por ser la organización internacional con más atribuciones legislativas (porque algunos de sus actos legislativos vinculan tanto a las instituciones como a los propios Estados miembros, y su política exterior que es significativa en la escena internacional), así como por la importancia de todas las naciones que quieran obtener un desarrollo, económico, político, social y cultural.

\subsection{Los círculos de integración}

Desde hace siglos atrás estuvieron presentes las ideas integracionistas de cooperación entre los países y con mayor razón aquellos que compartían un territorio continental; en ese contexto, con la creciente globalización se han acentuado los procesos de integración junto al predominio del modelo económico de libre mercado. En Europa, surge la Comunidad Europea hoy Unión Euro- pea como una institucionalidad supranacional y con atribuciones en el ámbito político, jurídico, económico-comercial y $\underline{\text { sociall }}^{6}$. Asimismo, este proceso de integración europea ha experimentado más de una docena de reformas en $50 \underline{\text { años}}{ }^{7}$ y de modo particular, en el Tratado de Lisboa por el que se modifican el Tratado de la Unión Europea y el Tratado Constitutivo de la Comunidad Europea (que pasa a denominarse Tratado de Funcionamiento de la Unión Europea) ${ }^{8}$. El Tratado de la Unión Europea (en adelante UE), adoptado en Maastricht en 07 de febrero de 1992, modificado por los Estados miembros, en su artículo A afirmaba que "... la creación de la Unión es una nueva etapa en el proceso creador de una unión cada vez más estrecha entre los pueblos de Europa". Sin embargo, A. Mangas señala que:

“... la Unión Europea no es una nueva organización internacional. Los Estados miembros no han querido que posea personalidad jurídica internacional. Las tres organizaciones internacionales existentes, la CECA, la CE y la CEEA o EURATOM, sobre las que se funda la Unión, conservarán por separado su carácter de sujetos de derecho internacional (artículos 6 CECA, 210 CE y 184 CEEA)" .

El contexto en que se ratifica el Tratado de Lisboa se da en una marco distinto del que había en el momento de la firma de los anteriores tratados. Por un lado, las condiciones exteriores, caracterizadas principalmente por la recesión económica (la repercusión de las sucesivas crisis monetarias que llevaron a la modificación de las bandas fluctuantes de los tipos de cambio del Sistema Monetario Europeo) que hizo que la Europa del bienestar se había roto con la última crisis financiera internacional (que se inicia en el 2008), y el debate actualmente está sobre el modelo de sociedad y la clase de Estado que quieren los europeos, evaluando si es necesario reformar el estado de bienestar, los estados y los ciudadanos de a pie que vivieron por encima de sus posibilida-

6 Cecchini, Paolo. (1994). La Unión Europea: eficacia y democracia. España, Edit. McGraw-Hill.

7 Al respecto, citaremos como los hechos más importantes en el difícil camino de la construcción europea: el Proyecto de un Tratado de la Comunidad Política europea, que llega a ser rechazado por la Asamblea Nacional francesa (1953); el informe de un comité de embajadores, sobre la Comunidad Política Europea (1961 y 1962); el Informe Davignon, realizado por encargo de la Cumbre Europea de la Haya (1969); el Informe Tindemans, sobre la Unión Europea (1975); el Informe de Londres de los Ministros de Asuntos Exteriores comunitarios sobre la Cooperación política Europea, con aportes importantes para la mejora de la misma (1981); la Declaración de Stuttgart de los Jefes de Estado o de Gobierno, para el fortalecimiento de la construcción europea (1983). El Parlamento Europeo aprueba el Proyecto Spinelli sobre el Tratado Constitutivo de la Unión Europea (1984); la entrada en vigor del Acta Única que incorpora, entre otras cosas, la cooperación política en el sistema de Tratados de la CE (1987); y la Cumbre Europea adopta en Maastricht el Tratado de la Unión Europea (1992).

8 El hecho histórico se realizó en Lisboa el 13 de diciembre del 2007 y se ratificó este instrumento jurídico el 26 de septiembre del 2008 y publicado en el BOE el 27 de noviembre del 2009 y entró en vigor el 01 de diciembre del 2009.

9 Mangas Martín, A. (1994). Tratado de la Unión Europea y tratados constitutivos de las Comunidades Europeas. Madrid, Tecnos, p. 22. 
des. Estos y otros aspectos más ${ }^{10}$ están llevando a una justificación a los euroescépticos, que señalan que la dimensión europea dificulta la salida de la crisis. De otro lado, en el ámbito interno de la comunidad, los contrarios del Tratado de la UE siempre lo presentaron como un peligro para la soberanía de los Estados, así como la antesala de una Europa conducida desde Bruselas, y ello hizo que llovieran críticas contra la burocracia. Tales hechos llegaron a sectores sensibilizados por los nuevos movimientos nacionalistas ${ }^{11}$.

Ahora bien, como todos sabemos, la Unión Europea es un bloque de integración conformado por 27 países $^{12}$, de los cuales hasta ahora participan 16 Estados en la moneda común y se les conoce como la Eurozona o Zona Euro, que viene a ser el conjunto de Estados miembros de la Unión Europea que han adoptado el Euro como moneda oficial (hasta ahora 16 Estados), formando así una unión monetaria. Su creación data del 01 de enero de 1999. La autoridad monetaria que controla la eurozona es el Eurosistema. La autoridad económica y política reside en el Eurogrupo y en la Comisión Europea.

En ese orientación, dentro de esta estrategia integracionista económica y comercial o los denominados círculos concéntricos de integración, se producen otros acuerdos como la Asociación Europea de Libre Comercio (EFTA), conformada por Suiza, Islandia, Liechtenstein y Noruega aunque Suiza ratificó en referéndum su no integración a la $\mathrm{CE}^{13}$, acuerdo este cuya finalidad es crear el llamado Espacio Económico Europeo (EEE) junto a la UE, y el primer paso de una futura ampliación de la Comunidad Europea implicaría que estos países en el futuro podrían pasar a ser socios de la UE. Sin embargo, existen desacuerdos en la Unión por parte de los denominados países grandes (Alemania, España, Francia, Italia, Reino Unido) con los pequeños (Luxemburgo, Irlanda, Portugal, Grecia, Dinamarca, Bélgica y Holanda), en lo que se refiere fundamentalmente a la reforma de las instituciones destinadas a abrir un espacio a estos países que están negociando su adhesión. En otras palabras, la ampliación tendría consecuencias en los países con mayor densidad poblacional, en cuanto a la presentación en los principales órganos de la Unión. Anteriormente existían problemas que fueron superados como los votos en el Consejo de Ministros (referente a las votaciones por mayoría cualificada con voto ponderado), en el turno rotatorio de la Presidencia del Consejo de Ministros, y el número de miembros de la Comisión Europea. Asimismo, los países grandes exigen que la reforma comience antes de la ampliación; en cambio, los países pequeños quieren que la ampliación se lleve con la mayor rapidez posible y sin reformas institucionales.

En cuanto a los países del este de Europa, la Unión reservó una vía de acercamiento que sería necesariamente más lenta. Los acuerdos de asociación fueron en un primer momento un primer paso de aproximación reservado a tres países de la Europa Oriental, para luego incorporarlos (República Checa, Hungría y Polonia). El bloque de países de la ex URSS, o Comunidad de Estados Independientes (CEI), sólo recibiría ayudas y una cooperación fundamentada en la Carta de la Energía, proyecto que en la actualidad camina con dificultades.

En otros continentes tenemos otras iniciativas de integración, como la Asociación de Naciones del Sudeste Asiático (ASEAN) ${ }^{14}$ y sostiene dife-

10 En la UE existe insolvencia del estado y esto va conduciendo a un replanteamiento sobre el Euro (moneda de la UE). Por citar un ejemplo, Alemania renunció a una moneda fuerte (el marco Alemán) y hoy existe una gran sensibilidad del ciudadano porque ya Alemania cumplió con todas las exigencias de integración, en cambio otros Estados de la Unión como Grecia, Italia, España y Portugal están en serios problemas económicos y financieros.

11 Deutsch, James. (1985). El nacionalismo y sus alternativas. Argentina, Editorial Paidós, p.12.

12 Los países que integran la UE son: Austria (1995), Bélgica (1952), Bulgaria (2007), Chipre (2004), República Checa (2004), Dinamarca (1973), Estonia (2004), Finlandia (1995), Francia (1952), Alemania (1952), Grecia (1981), Hungría (2004), Irlanda (1973), Italia (1952), Letonia (2004), Lituania (2004), Luxemburgo (1952), Malta (2004), Países Bajos (1952), Polonia (2004), Portugal (1986), Rumania (2007), Eslovaquia (2004), Eslovenia (2004), España (1986), Suecia (1995), Reino Unido (1973). Países en vías de adhesión: Croacia. Países candidatos: Antigua República Yugoslava de Macedonia, Islandia, Montenegro, Serbia, Turquía. Candidatos potenciales: Albania, Bosnia y Herzegovina, Kosovo, según la Resolución No 1244 del Consejo de Seguridad de Naciones Unidas. Véase en: http://europa.eu/about-eu/ countries/index es.htm

13 Algunos datos de los países de la EFTA ante el nuevo desafío del espacio económico europeo: población total de la EFTA 32.8 millones; en el comercio mundial, sus exportaciones representan el $6.6 \%$ ante un $40.6 \%$ de la CE; y en sus importaciones, un $6.9 \%$ ante un $39.5 \%$ de la CE. Asimismo, la mayoría de los candidatos a la ampliación cumplen con los criterios de convergencia con la CE y tienen sus monedas vinculadas al ECU.

14 La Organización Regional de Estados del Sureste Asiático se fundó para acelerar el crecimiento económico y fomentar la paz y la estabilidad regional entre sus países miembros (Indonesia, Malasia, Filipinas, Singapur, Tailandia, Brunei, Vietnam, Laos, Myanmar, Camboya). La ASEAN ha establecido un foro conjunto con Japón y sostiene un acuerdo de cooperación con la Unión Europea (UE). Su secretariado permanente se encuentra en Yakarta. Ver: The ASEAN Declaration, Bangkok, Tailandia, 08 de agosto de 1967. 
rentes acuerdos de cooperación ${ }^{15}$, la Asociación Sudasiática para Cooperación Regional (SAARC), Asociación de Países del Sur Asiático (Afganistán, Bangladesh, Bután, India, Maldivas, Nepal, Pakistán, y Sri Lanka) establecida el 08 de diciembre de 1985. En el ámbito africano tenemos la Unión Africana (UA) que viene a ser una organización supranacional dedicada a incrementar la integración económica y política, y a reforzar la cooperación entre sus Estados miembros. Reemplaza a la Organización para la Unidad Africana (UA) que está inspirada en la Unión Europea. Marruecos es el único país del continente que se mantiene fuera de la UA. Otros países como España, el Reino Unido o Francia, que cuentan con territorio en África, tampoco forman parte de esta organización.

Otra organización es la Autoridad Intergubernamental de la Comunidad en Desarrollo (SADC) que en un primer momento se inicia en Lusaka, Zambia, el 01 de abril de 1980, coordinando los proyectos de desarrollo de sus miembros ${ }^{16} \mathrm{y}$ posteriormente, se vuelve Comunidad el 17 de agosto de 1992 con la firma de Tratado en Windhoek, Namibia, en 1992. La Unión del Magreb Árabe es un acuerdo de integración comercial firmado por los jefes de Estado de Marruecos, Argelia, Túnez, Mauritania y Libia ${ }^{17}$.

Es de destacar también el Foro APEC (AsiaPacific Economic Cooperation o, en español, Cooperación Económica del Asia-Pacífico), que es un foro multilateral, creado en 1989 , que trata temas relacionados con el intercambio comercial, coordinación económica y cooperación entre sus integrantes. Como mecanismo de cooperación y concertación económica, está orientado a la promoción y facilitación del comercio, las inversiones, la cooperación económica y técnica, y al desarrollo económico regional de los países y territorios de la cuenca del Océano Pacífico. La suma del Producto Nacional Bruto de las 21 economías que conforman el APEC equivale al 56\% de la producción mundial, en tanto que, en su conjunto, representan el $46 \%$ del comercio global.

En el ámbito de América del Norte se está aplicando el Tratado de Libre Comercio (NAFTA) de Canadá, Estados Unidos y México. Existen diferencias y afinidades entre la Comunidad Europea y el NAFTA. Este último no constituye una unión aduanera, sino que se limitará a eliminar progresivamente las barreras comerciales entre sus miembros, y los países firmantes mantendrán sus políticas comerciales con terceros países de forma totalmente autónoma. La UE, en cambio, defiende un espacio comercial común frente a terceros de forma coordinada. El NAFTA, podríamos decir, se parece más a la EFTA que a la Unión Europea. En junio de 1990, los Estados Unidos impulsaron la Iniciativa para las Américas, con el objetivo principal de negociar zonas de libre comercio con grupos de países de América Latina y El Caribe. Como consecuencia de esta iniciativa, distintos países de América Latina han empezado negociaciones bilaterales o multilaterales entre ellos, y/o han decidido estrechar más aún los acuerdos de integración ya existentes; todo esto no pasó de ser una iniciativa que se quedó inactiva por falta de voluntad política de los países latinoamericanos.

Sin embargo, tenemos que comentar que en la actualidad vienen predominando los acuerdos comerciales y bilaterales para ampliar los bienes y servicios entre los países como los tratados de libre comercio (TLC) y que no son incompatibles con los procesos de integración. Ahora bien, en este punto nos gustaría hacer algunas anotaciones por la importancia que viene tomando en esta última década, entonces surge la interrogante: ¿qué es un tratado de libre comercio? Un tratado de libre comercio es un acuerdo entre dos o más países, o entre un país y un bloque de países que es de carácter vinculante. La importancia para los países en vías de desarrollo, por ser economías pequeñas, es que su desarrollo sostenido depen-

15 El Acuerdo celebrado entre la Asociación de Países del Sudeste Asiático (ASEAN), conformada por Filipinas, Indonesia, Malasia, Singapur y Tailandia, y la Comunidad Económica Europea adquiere también una significación jurídica institucional importante, no solo por los términos mismos del acuerdo en relación a su vínculo jurídico entre ambos esquemas, sino también al hecho que sienta un precedente sobre la política de la CEE en relación a otros países en desarrollo. Sobre este tema, existe una amplia bibliografía, véanse, Wagner, N. (1987). Drittes ASEAN-Gipfeltreffen in Manila, Singapur. Comentario extenso desde el 16 de diciembre de 1987. Bruselas; Tasker, R. (1987). "Leaders turno ut to support Aquino despite risk. 18 minute de solidarity”. En: Far Eastern Economic Review, 24 de diciembre de 1987, p. 8 y ss; Mols, M. (1988). “ASEAN luego de la tercera reunión cumbre”. En: Estudios Internacionales. N81, p. 45 y ss.

16 Sus miembros son: Angola, Botswana, Congo, Lesoto, Madagascar, Malawi, Mauritius, Mozambique, Namibia, Sudáfrica, Swazilandia, Tanzania, Zambia y Zimbabwe. Su sede está en Gaborone, Botswana.

17 Sus instituciones más relevantes son el Consejo Presidencial, compuesto por los jefes de Estado de los cinco países miembros bajo la presidencia por turnos de cada uno de ellos durante seis meses; el Consejo de Ministros de Asuntos Exteriores; el Comité de Seguimiento, compuesto por un miembro de cada gobierno; el Consejo Consultivo, compuesto por diez diputados de cada parlamento nacional; un Órgano Judicial compuesto por dos jueces de cada país, encargado de arbitrar los litigios entre Estados miembros; y una Secretaría General del Consejo Presidencial. Marrakech, Marruecos, 17 de febrero de 1989. 
de del crecimiento de su comercio exterior y de la inversión privada nacional y extranjera, y con el inicio de las negociaciones para la firma de un TLC, los países decidieron dar un paso hacia una verdadera expansión exportadora y como consecuencia, lograr más empleos mejor pagados y mayor diversificación de la oferta exportable. Entre sus objetivos generales podemos mencionar el acceso preferencial permanente de sus exportaciones; incremento de las exportaciones, eliminando distorsiones causadas por aranceles unilaterales, así como contribuir a mejorar la calidad de vida de las personas a través del acceso del consumidor a productos más baratos y de mayor calidad y variedad, además de crear mecanismos para defender los intereses comerciales de los países que suscriben el TLC.

\subsection{La búsqueda de un marco institucional de los países desarrollados y en desarrollo}

En la actualidad la tendencia mundial es integrar mejor a los países en desarrollo de la economía mundial, que participen del crecimiento de la actividad, de los intercambios y los progresos económicos y técnicos. En ese contexto, la comunidad internacional y los países desarrollados -agrupados o individualmente- sugieren que:

“... el paso de la dimensión nacional a la escala regional puede constituir para muchos de los Países en vías de Desarrollo (PVD) la primera etapa de una ampliación de su espacio económico. La cooperación y la integración regionales representan, además, un instrumento importante del fomento del desarrollo económico de los PVD y pueden, por otra parte reducir las tensiones políticas y militares de naturaleza regional y constituir un apoyo a los procesos democráticos nacionales ${ }^{18 "}$.

Asimismo, la apertura de los mercados de integración y la creciente globalización tiene incidencia directa en América Latina; sin embargo, existen dificultades en ese tortuoso camino y está claro que no se logrará la integración con discursos bolivarianos o sanmartinianos o chavistas, sino con un nuevo marco jurídico de integración económica. El Estado de derecho y su inserción es inevitable en estos países de la comunidad internacional para no ser marginados del centro del poder. Desde ese punto de vista, los países Latinoamericanos tratan de reforzar su posición y asumir más responsabilidad internacional en el ámbito económico y comercial mediante sus organismos de integración regionales.

\section{El Nuevo Marco Jurídico de Integración Económica en los Países en Desarrollo de América Latina.}

Como respuesta a no ser marginados de los centros de poder económico y comercial, los países de América Latina ${ }^{19}$ se ven en la obligación de integrarse para beneficio mutuo y un mejor posicionamiento en el mercado internacional.

Como ya señalamos, desde la postguerra hasta nuestros días, vivimos una tendencia creciente hacia un agrupamiento regional de países en un mundo globalizado respecto a las relaciones económicas y comerciales, en el que los grandes actores regionales tienen la posibilidad de actuar con éxito, y las regiones más desfavorecidas pueden quedar cada vez más postergadas en el mañana. En palabras de Franco Montoro:

“... la integración de América Latina no es apenas una aspiración o un punto de vista de algunos grupos, sino también es una opción facultativa. Ella es hoy un imperativo histórico y camino necesario para el desarrollo económico, social y político de los países de la región y para su integración competitiva en la economía mundial". ${ }^{20}$

Es decir, América Latina no solo justifica la necesidad de asumir estas iniciativas y avances de su integración como región-acuerdos tendentes a crear subagrupaciones de libre comercio e inclusive mercados comunes-, sino que trata de fortalecer la conciencia de una responsabilidad internacional colectiva e integrarse en la economía mundial. La búsqueda de una nueva expresión de las relaciones de los países desarrollados y América Latina es uno de sus objetivos.

18 Comisión de las Comunidades Europeas: Comunicación de la Comisión al Consejo y al Parlamento Europeo. La política de cooperación al desarrollo en el horizonte 200 - Aplicación del Tratado de Maastricht. Bruselas, 16 de septiembre de 1992, p. 64.

19 Luis Castellanos señala: "A este respecto vale destacar cómo reiteradamente se ha planteado en los organismos regionales -CEPAL y SELA-, que la actuación conjunta y coordinada de América Latina puede garantizar una respuesta efectiva al proteccionismo de los centros y un trato simétrico en las relaciones con ellos". En: "Hacia una revisión de las relaciones con la Comunidad Europea". En: Nueva Sociedad. $\mathrm{N}^{\circ} 106$, p. 124. Véase también, sobre las limitaciones de la CE como interlocutor político, en De la Serre, F. (año). Foreign Policity og the European Communities. Ciudad, editorial; Macridis, R. (1989). Foreign Policity in World Politics. New Jersey, Prentice Hall, Roy c. Ed., pp. 345-373.

20 Franco Montoro, A. (1993). Perspectivas de integracao da América Latina. Sao Paulo, ILAM, p. 1. 
América Latina, en el nuevo mapa de las relaciones económicas internacionales, ha pasado de la década perdida ${ }^{21}$ de los años 80 , a la década de la esperanza en los 90 y en estos últimos años, a la década de la estabilidad, el desarrollo y la integración.

El comercio exterior en Latinoamérica se prevé que podría disminuir hasta un $20 \%$ debido a la crisis internacional que afecta a sus principales socios comerciales, en ese sentido la CEPAL en un estudio, estima que el panorama de la inserción internacional de América Latina y El Caribe 2011-2012 no será muy optimista, pese que Latinoamérica es la región del mundo con mayor crecimiento del volumen exportado en el último semestre del 2012 y en los primeros cuatro meses de 2012. La crisis europea y el poco dinamismo de Estados Unidos, Japón y China afectarán su desempeño exportador en los meses posteriores. Ante este escenario, la CEPAL prevé que el valor de las exportaciones totales de la región continuará aumentando durante el próximo trienio, aunque a tasas menores de la registradas en años anteriores (5\% anual entre el 2013 y el 2015, versus $20 \%$ anual en promedio durante la segunda mitad de la década pasada) y, mirando hacia el futuro, recomienda elevar el crecimiento en aquellos desafíos de la oferta productiva que persisten: productividad, innovación, educación, infraestructura, logística y transporte ${ }^{21}$.

\subsection{La dimensión y desarrollo de la integra- ción en América Latina.}

Podemos encontrar la idea sobre la formación de una gran nación de repúblicas del continente Latinoamericanos en las propuestas del libertador Simón Bolívar en el Congreso Anfictiónico de Panamá del año de $1986^{22}$. Posteriormente, se da un primer paso en la realización de convenios bilaterales de comercio y pagos suscritos entre los países de América del Sur a raíz de las crisis de los años 30. Tras la Segunda Guerra Mundial, se abre el diálogo entre los países de la región, cuando, paralelamente, se empiezan a discutir y a poner en vigencia las distintas experiencias de integración económica en la diferentes áreas del mundo, conscientes de la interdependencia y la necesidad de cooperar (objetivos comunes de los Estados miembros).

En ese sentido, cuando se habla de integración en América Latina se hace referencia a un determinado ámbito o espacio del continente latinoamericano que es necesario delimitar. La CEPAL, en la II Cumbre Iberoamericana, señala: "Por América Latina se entenderá al conjunto de 19 países; el termino ibérico se reservará para agregados que incluyan a España y Portugal”. A su vez, estos se extienden desde el extremo septentrional y el istmo centroamericano (México, Guatemala, El Salvador, Honduras, Nicaragua, Costa Rica y Panamá), pasando por El Caribe isleño (Cuba y República Dominicana), por la Cordillera de los Andes (Venezuela, Colombia, Ecuador, Perú, Bolivia y Chile) hasta el cono sur (Paraguay, Brasil, Uruguay y Argentina) ${ }^{23}$. Estos Estados, para el año de 2012, se estima que alcanzarán los 800 millones de habitantes en conjunto, por lo que representan un bloque importante en los organismos internacionales como las Naciones Unidas.

Estas etapas y modalidades de integración en América Latina se estudian también desde diferentes puntos de vista. Trataremos de resumir algunos de los hechos referentes a los principales esfuerzos de integración, entre estos tenemos: la Secretaría General Iberoamérica (SEGIB), Asociación de Estados del Caribe (AEC), Organismo Andino de Salud - Convenio Hipólito Unanue (ORAS-CONHU), Instituto Interamericano de Cooperación para la Agricultura (ILCA), Organización del Tratado de Cooperación Amazónica (OTCA), Proyecto de Integración y Desarrollo de Mesoamérica (Proyecto Mesoamérica), Organización Panamericana de la Salud (OPS), la Corporación Andina de Fomento (CAF), Asociación Latinoamericana de Integración (ALADI), Comisión

21 Al respecto, P. Meller señala: "Las tasas de promedio anuales de crecimiento habían sido del 5.7\% para las dos décadas anteriores a 1980 (1960-1980); durante el periodo 1980-1990, el PIB creció un 1.3 \% anual. Dado que las tasas de la población son relativamente elevadas (2.2 $\%$ durante los años 80; $2.5 \%$ en las décadas de 1960 y 1970), el nivel medio de renta per cápita en 1990 era un $9 \%$ inferior al de 1980 . En algunos países como Argentina, Bolivia, Perú y Venezuela, será incluso más bajo que el de 1970". Véase en "Ajuste y reformas económicas en América Latina: problemas y experiencias recientes”. En: Pensamiento Iberoamericano. N²2-23. Tomo II. Julio, 1992 - junio, 1993, p. 15. Ver, Moneta, C.: “L'integration Latinoamericaine Dans le contexte International des années 1990". En: Problème d' Amérique Latine. $\mathrm{N}^{\circ} 7.1992$, p. 29.

22 Ver la presentación del documento por la Secretaría Ejecutiva de la CEPAL: Barcena, Alicia. (2012). "Crisis Internacional desacelera comercio latinoamericano". En: Revista de Mercados \& Tendencias. Edición N 65.

23 Para profundizar el estudio sobre este tema, véase Townsend Ezcurra, A. (1988). La Nación de las Repúblicas: proyecto latinoamericano del Libertador. Caracas, Ed. Ministerio de Relaciones Exteriores de Venezuela, p.75. 
Económica para América Latina (Cepal), Fondo Latinoamericano de Reservas (FLAR), Organización de Estados Americanos (OEA), Sistema de Integración Centroamericana (SICA), el Área Libre de Comercio de las Américas ( Alca), y el Sistema Económico Latinoamericano (Sela). La representación y coordinación a escala internacional sería asignada al Sela, que fue constituido en Panamá, el 31 de julio de $1975^{24}$, organismos regionales que no tienen los mecanismos permanentes de intercambio de cooperación, información y de dialogo $\mathrm{o}^{25}$ para conocer la dimensión y los alcances de sus actividades.

Sin embargo, el mercado Centroamericano (MCCA), la Alternativa Bolivariana para América Latina y el Caribe (Alba), el Mercado Común del sur (Mercosur), la Unión de Naciones del Sur (Unasur) y la Comunidad Andina de Naciones (CAN), son procesos de integración que tienen nuevos empujes.

En el ámbito de la concertación política se tuvieron otras iniciativas de integración, a raíz de la revelación de la crisis de la deuda externa de los países latinoamericanos; por ello se buscan nuevas formas de concertación con los diferentes gobiernos de la región y de otros continentes como: Grupo Contadora, Grupo de Apoyo a Contadora, Consenso de Cartagena, el Grupo de Embajadores de América Latina ante las comunidades europeas que viene a establecer un mecanismo concertado de diálogo y representación; asimismo, por su carácter informal, los contenidos han ido variando en función de los temas que las circunstancias generaban ${ }^{26}$, tenemos al Grupo de Río ${ }^{27}$ o de los Ocho que se desenvolvió como como un organismo informal de consulta y concertación política frente a otros organismos ${ }^{28}$ para, de ese modo, influir a escala regional e internacional como fue en su momento el grupo de los 77 y el Movimiento de Países No Alineados

Hoy surgen nuevos mecanismos de consulta y concertación política que vienen a ser espacios políticos generalmente regionales, que coordinan esfuerzos de integración, cooperación y desarrollo y que se adaptan a las nuevas realidades, y apoyan los esfuerzos de los esquemas formales, como el caso del Grupo de Río, que es la base y sustento para la creación de un nuevo organismo denominado Comunidad de Estados Latinoamericanos y Caribeños (Celac) ${ }^{29}$, Proyecto Mesoamérica, el Grupo de los Tres (G3), Conferencia Iberoamericana, Cumbre América Latina y El Caribe - Unión Europea $^{30}$ (ALC-UE), Alianza del Pacífico, Cumbre de las Américas, Grupo de los tres, Organismos Especializados Regionales, Organismo para Proscripción de Armas Nucleares en la América Latina y El Caribe, Foro del Arco del Pacífico Latinoamericano, Cumbre América Latina y El Caribe sobre Integración y Desarrollo (CALC), Cumbre América del Sur- África (ASA), Cumbre América Latina y El Caribe (CALC), Foro Empresarial Árabe -Sudamericano (Aspa), que viene a ser el espacio de encuentro entre los líderes económicos y empresariales de ambas regiones, y la Unión de Naciones Suramericanas (Unasur).

Sin embargo, los resultados de integración en el grado de cumplimiento de ciertos objetivos presentan avances de algunos sectores y retrocesos en determinados aspectos como, por ejemplo, los criterios económicos de integración. Es decir, el hecho de levantar las barreras comerciales, el costo del transporte, los grados de industrialización o

24 Asimismo, el ILPES indica: "Se excluyen 14 países y 6 Estados Asociados de la región, que no son hispanos o lusoparlantes (entre Estados Asociados está Puerto Rico, donde también se habla español). Como El Caribe, los países excluidos se relacionan con la Comunidad Europea en forma diferente, pues la mayoría se vincula con los Acuerdos de Lomé. En ese sentido, se abre en el texto una única excepción: República Dominicana, que en 1989 paso a beneficiarse de estos acuerdos»; en El vínculo Iberoamérica-Comunidad Europea. Planes, Políticas y estrategias de desarrollo, en la VIII Conferencia de Ministros y Jefes de Planificación de América Latina y El Caribe, del 22 al 26 de marzo de 1992, p. 17.

25 El Convenio constitutivo de SELA lo define como un organismo regional de consulta, coordinación, cooperación y promoción económica y social conjunta de carácter permanente. Véase: SELA. (1986). Presente y futuro de la cooperación económica intralatinoamericana. Buenos Aires, INTAL. Véase, SELA (1979). SELA en Acción. N9, pp.30-31. Véase también al respecto Manfred Wilhelmy, V. W. (1988). "Las políticas latinoamericanas hacia Europa Occidental: los niveles nacional, regional y subregional”. En: Síntesis. N4, p. 105 y ss.

26 Berrocal, L. (1980). El diálogo euro-latinoamericano, ¿más allá de un neocolonialismo larvado? Ciudad, RIOE, p. 950.

27 Este organismo carece de una estructura permanente. La secretaría es ejercida de forma rotatoria entre los representantes de los países miembros, que son: Argentina, Bolivia, Brasil, Chile, Colombia, Costa Rica, Cuba, Ecuador, El Salvador, Guatemala, Haití, Honduras, México, Nicaragua, Panamá, Perú, Uruguay y Venezuela.

28 Véase de Juan y Peñalosa, R. (1991). "La CEE formaliza e impulsa sus relaciones con América Latina". En: Boletín ICE, del 15 al 21 de abril de 1991, pp. 1.191-1.203.

29 Fundado en 1986, en Río de Janeiro, como mecanismo permanente de consulta y concentración política en la reunión de Cancilleres de Grupo de Contadora y de apoyo, adoptó el nombre de Grupo de los Ocho. En 1987, en Acapulco, se realizó la primera reunión de Jefes de Estado; en febrero de 1988, Panamá fue suspendido temporalmente, y en 1990 adoptó la actual denominación.

30 Véase De la Iglesia J.P. (1988). "Las relaciones entre Europa de los Doce y América Latina. Un proceso de cambio acelerado". En: Pensamiento Iberoamericano. $\mathrm{N}^{\circ} 13$, p. 146. 
renta por habitante, la estructura de producción, la estabilidad monetaria y la política económica, son cuestiones a resolver o presentan dificultades en sus soluciones. Tales factores conducen a un gran sector de latinoamericanos al escepticismo y la reserva, lo contrario de lo que manifiestan las declaraciones de los gobiernos de turno. Otros, como Rosenthal, G., señalan que se han de tener en cuenta ciertas apreciaciones sobre la evolución del proceso de integración de América Latina, según cuatro objetivos estrechamente vinculados entre sí:

“... que la integración resulte funcional a los objetivos de la política económica nacional; que el proceso entrañe para cada país beneficios tangibles y que, en todo caso, excedan los costes del proceso; que los compromisos integradores formen parte de los proyectos políticos nacionales, y que la integración sea una empresa que suscite el apoyo de amplios estratos de la población de cada país ${ }^{31}$ ".

\subsection{Los esquemas de integración de América Latina.}

Como ya dijimos, las nuevas realidades exigen buscar nuevos espacios de integración económica y jurídica entre las naciones que tienen lazos históricos, geográficos e intereses económicocomerciales para no ser marginados del sistema económico internacional; asimismo, la apertura de mercados de integración y la globalización tienen incidencia directa en Latinoamérica y surgen nuevos desafíos de integración, en algunos se profundizan y otros son de reciente creación. En los países de América Latina está en vigencia el comercio mundial para esta década, y su oportunidad dependerá del fortalecimiento y dinámica de los espacios económicos regionales actuales. Veamos los rasgos básicos de estos organismos regionales que, a nuestro entender, son los más importantes en relación con el presente estudio.

En ese sentido podemos decir, en el plano normativo institucional, que la integración tuvo dos momentos importantes en su construcción. El primero, comenzó decididamente en los años
60. Los países latinoamericanos emprendieron un proceso de integración como consecuencia de la toma de conciencia sobre la importancia que tenían sus intereses en las relaciones económicas internacionales. Producto de este fenómeno de integración, aunque sin mayor análisis, tenemos los tratados de la Organización de Estados Centroamericanos (ODECA), fundado en 1951 en San Salvador, mediante la firma por los Ministros de Exteriores de Costa Rica, Guatemala, Honduras y Nicaragua ${ }^{32}$; el MCCA, establecido en 1958 con el Tratado Multilateral de Libre Comercio de Integración Económica, institucionalizado por el Tratado General de Integración Económica de América Central, firmado en Managua el 13 de diciembre de 1960 (MCCA) $)^{33}$, que luego pasó a convertirse en el SICA (Sistema de Integración de Centro América) incluido el país de Belice, cuyo objetivo es impulsar el desarrollo y su integración económica.

Otras organizaciones son la Asociación Latinoamericana de Libre Comercio (ALALC), establecida por el Tratado de Montevideo del 18 de febrero de 1960, posteriormente sustituido por la Asociación Latinoamericana de Integración (Aladi), fundada el 12 de agosto de 1980, mediante el Tratado de Montevideo; el Pacto Andino, fruto del Acuerdo de Cartagena (Colombia), del 26 de mayo de 1969.

El segundo momento diríamos que empieza con un nuevo rostro, nuevas ideas y que se adaptan a las nuevas realidades globales y regionales, entre cuyas organizaciones podemos mencionar:

a. La Asociación Latinoamericana de Integración (Aladi). Este acuerdo comercial fue creada el 12 de agosto de 1980 y representa en conjunto 20.4 millones de kilómetros cuadrados y más de 520 millones de habitantes al 2011. Está integrada por catorce países. A los fundadores (Argentina, Bolivia, Brasil, Chile, Colombia, Ecuador, México, Nicaragua, Paraguay, Perú, Uruguay y Venezuela) se integraron Cuba y Panamá como miembros plenos y está abierta su adhesión para cualquier Estado Latinoamerica-

31 Véase al respecto Rosenthal, Gert. (1989). “Repensando la integración”. En: Pensamiento Iberoamericano. ํ15, p.14.

32 Al respecto, Rosenthal, G. (1989) señala que se han de tener en cuenta ciertas apreciaciones sobre la evolución del proceso de integración en América Latina, según cuatro objetivos estrechamente vinculados entre sí: “... que la integración resulte funcional a los objetivos de la política económica nacional; que el proceso entrañe para cada país beneficios tangibles y que, en todo caso, que los compromisos integradores formen parte de los proyectos políticos nacionales y que la integración sea una empresa que suscite el apoyo de amplios estratos de la población de cada país". Véase, "Repensando la integración”. En: Pensamiento Iberoamericano. Nº15, p. 14.

33 Lo integran los países de Costa Rica, El Salvador, Guatemala, Honduras, Nicaragua y Panamá. 
no que lo solicite. El nuevo Tratado de la Aladi ${ }^{34}$ sustituye al ALAC después de dos decenios de existencia y de un balance desafortunado en cuanto a los objetivos principales a cumplir. Se empieza una nueva etapa que tiene una connotación más pragmática respecto a los compromisos, haciéndolos menos obligatorios, e incorporando nuevas formas operativas y de procesos de integración económica regional con varias velocidades y grados de compromiso, con el objeto final de establecer -progresivamente- el mercado común latinoamericano a largo término. Ese Tratado de Montevideo también provee a los países miembros de una adecuada cobertura jurídica en el ámbito internacional “... frente a las disposiciones del artículo XXIV del GATT respecto de los acuerdos de preferencias comerciales que hayan concertado entre sí o subregionalmente ${ }^{35}$ ". La ALADI, según la Cepal, lo reduce a un plano esencialmente de "cooperación comercial latinoamericana ${ }^{36 " ; ~ o t r o s, ~ e n ~ c a m b i o, ~ l o ~ d e f i n e n ~}$ por las características del tratado como una zona de preferencias recíprocas y que, por su flexibilidad, puede convertirse en una simple zona de libre comercio o proyectarse a un mercado común ${ }^{37}$. Sus mecanismos de integración son de preferencia arancelaria regional, acuerdos de alcance regional y acuerdos de alcance parcial ${ }^{38}$. Actualmente tiene relaciones con las demás agrupaciones subregionales de integración. b. Mercado Común Centro Americano (MCCA). Fundado el 13 de diciembre de 1960, se rige por el Tratado de Managua y sus protocolos modificatorios. Lo conforman Guatemala, El Salvador, Honduras, Nicaragua y Costa Rica; su población representa el $6.5 \%$ y su territorio un $2.2 \%$ del total de América Latina, su comercio no es de mucha trascendencia con Latinoamérica, excepto México y en su mayor parte Estados Unidos. Este bloque económico y político busca la integración de un mercado común.

c. Comunidad Andina (CA). Es una organización regional económica y política, fundada en 1969 en un primer momento por Bolivia, Colombia, Chile, Ecuador y Perú. Anteriormente ${ }^{39}$ a 1996 era reconocida como Pacto Andino ${ }^{40}$. Chile abandonó la Comunidad ${ }^{41}$ en 1976 y Venezuela ingresa en 1973 para luego retirarse en el 2006 para formar su adhesión a MERCOSUR. Actualmente Argentina, Brasil, Uruguay y Chile son miembros asociados y México y Panamá son observadores. Actualmente una superficie de 3'798,000 km2 cuyo PBI nominal ascendía en el 2011 a US\$ 600,291. El objetivo es alcanzar un desarrollo integral, equilibrado y autónomo mediante la integración andina, suramericana y latinoamericana, así como profundizar las relaciones de cooperación con otros bloques regionales ${ }^{42}$. El Grupo Andino, por una parte, tiene un modelo de desarrollo de integración

34 Reemplazó a la Asociación Latinoamericana de Libre Comercio e introdujo notables cambios en la orientación del proceso de integración, con apertura a todos los países latinoamericanos. Los objetivos que se plantea son promover el desarrollo económico y social de forma equilibrada, mediante la intensificación y regulación del comercio entre los países de la región, el fomento de la complementación económica y el desarrollo de acciones de cooperación para la ampliación de mercados, con el objetivo final de conseguir el establecimiento de un mercado regional.

35 Como ejemplo tenemos la incorporación de los Acuerdos Argentino-Brasileño al marco normativo de la ALADI, que resultaba operacional y jurídicamente conveniente para ambos países, pues se evitaba su aprobación por el GATT. Véase García, H. (1992). El Tratado de Asunción del Mercado Común del Cono Sur (MERCOSUR): Algunas consideraciones. Santiago de Chile, CEPAL, LC/R.118, del 15 de enero de1992, p. 9; Moya Domínguez, M.T. (1983). "La Argentina ante el proceso de transición de la integración latinoamericana". En: Anuario argentino de Derecho Internacional. 1983. Vol. I, p. 10 y ss.

36 Véase el análisis de la Aladi, Vacchino, J.M. (1989). "Integración, cooperación y concertación en América Latina”. En: Documento N4 PNUD-Cepal (1989). América Latina y Europa Occidental en el umbral del siglo XXI. Ciudad, CEPAL, p. I y ss.

37 Véase Informativo Andino, I, septiembre de 1992, p. I y ss.

38 Ver Artículo II del Tratado.

39 Acuerdo de Cartagena: Cronología de la Integración Andina. Junta de Acuerdo de Cartagena, p. 43.

40 Cepal (1987). Relaciones económicas internacionales y de cooperación regional en América Latina y El Caribe. Santiago de Chile, Cepal, p. 324.

41 La Junta del Acuerdo de Cartagena la suscriben por primera vez en Bogotá, en 1969, los países de Bolivia, Colombia, Perú y Chile (que dejará de pertenecer al grupo en 1976), mientras que Venezuela se incorporará en 1973. Se trata de un acuerdo para crear un grupo de integración, para promover el desarrollo y crecimiento de los países miembros mediante la integración económica y social, programas de industrialización, del desarrollo de la agricultura, con un arancel externo común, de la canalización de los recursos para asegurar la distribución equitativa de sus miembros. En 1991, se acordó crear una zona libre de comercio para 1992. Véase "Organismes d'integracio a América Latina”. En: Revista CIDOB. N40, p. 27. Ver: Comisión del Acuerdo de Cartagena, en su XXIV Periodo de Sesiones Extraordinarias.

42 Se establece un sistema de acumulación regional con la excepción a la definición de productos originarios de los países en desarrollo, establecida por el Reglamento $N^{\circ} 3$ - 749/83 de la Comisión: Commission CE conclusions de la deuxiéme commission miixte Communauté Europeenne- Accord de Carthagene et ses Pays members. Lima, 10 y 11 de diciembre de 1990, Doc. S.N. 5329/90 (AMLAT) OR. es, Sen/ JJ/am. Véase, Acuerdos CEE/ALA/88-6. Ver: DOCE, NL 153, del 08 de junio de 1984, p. I. 
que pretende ir más allá de una simple zona de preferencias o de la formación de una zona de libre comercio. Por otra parte, a diferencia de la orientación de los años 70, en que su política de desarrollo se orientaba hacia la sustitución de importaciones, en la actualidad se encauza hacia la liberalización del comercio de acuerdo a las corrientes de pensamiento y acción de hoy en día ${ }^{43}$. De otro lado, la parte más crítica del problema es la concordancia entre el objetivo de alcanzar un acuerdo-marco dotado de la mayor flexibilidad, y el objetivo prioritario de perfeccionar un instrumento sustentativo y no solamente declarativo o de intenciones. Sin embargo, es de resaltar que 1995 es el plazo que el Grupo Andino se impuso en el diseño estratégico aprobado en la Reunión Presidencial de Galápagos, para llegar a la Unión Aduanera. La Decisión 324 de la Comisión del Acuerdo de Cartagena, de agosto de 1992, estableció el 30 de septiembre del mismo año “... como la fecha en que debía completarse la formación de la zona de libre comercio para todos los socios andinos ${ }^{44}$ ", excepto Perú, que suspendió su participación hasta fines de $1993^{45}$ y luego regresó. En la actualidad se viene sosteniendo que el CAN se integre a la UNASUR.

d. Mercado Común del Sur (Mercosur). Este Acuerdo Comercial es una unión aduanera todavía imperfecta, y tiene una población de más de 210 millones que viene a ser el 3.5\% de la población mundial y aglutina al $75 \%$ del Producto Bruto Interno (PBI) de Sudamérica. Es considerado el cuarto bloque económico y el mayor productor de alimentos del mundo. Tiene por objetivo una integración política, cultural, así como promover el libre intercam- bio y movimiento de bienes, servicios, personas y capital entre países. Se creó en 1985 por Argentina y Brasil y luego se incorporaron Uruguay (1988) y Paraguay (1991), Como estados asociados se encuentran Bolivia, Chile, Colombia, Ecuador y Perú y como observador México $^{46}$. Los antecedentes más cercanos se remontan a la conformación del Mercado Común del Sur (Mercosur) ${ }^{47}$, cuyos orígenes se remontan a la década de los 80 . Argentina y Brasil fueron encaminando sus compromisos pactados en un comienzo para, posteriormente, firmar nuevos acuerdos y acortar los plazos para alcanzar una integración más económica, mientras que Uruguay se fue incorporando paulatinamente por medio de unos protocolos del Programa de Integración y Cooperación Argentino-Brasileño. En 1990, Argentina y Brasil acordaron establecer un mercado común, al que se incorporaron también Paraguay y Uruguay. Así pues, en marzo de 1991, los cuatro países suscribieron el Tratado de Asunción para establecer el Mercado Común del Sur. En la actualidad, cuentan con 190 millones de consumidores, y PNB de US\$ 521 millones; en tanto que el Grupo Andino cuenta con 92 millones de consumidores y un PNB de US\$ 140 millones; y la Aladi, tiene 363 millones de consumidores. La CE, por su parte, tiene más de 360 millones de habitantes, un PBI de US\$ 600 millones y presenta un $22 \%$ del comercio internacional.

Sus objetivos fundamentales fueron definidos en el Compromiso de Acapulco para la Paz, el Desarrollo y la democracia, entre los que destaca la creación de un mercado ampliado; es decir, la integración de las economías de los

43 Para un análisis de las diferentes facetas del Grupo Andino véase "La primera zona de libre comercio". En: Revista del Grupo Andino, octubre-diciembre de 1991, pp. 4-31.

44 Véase Informativo Andino. $\mathrm{N}^{\circ} 1$, septiembre de 1992, p. 1

45 La ausencia temporal de Perú de la zona andina de libre comercio es a partir del 27 de agosto de 1992. Perú suspendió la totalidad de sus compromisos con respecto al programa de liberación hasta el 31 de diciembre de 1993, de acuerdo con la Decisión 321 de la Comisión de Acuerdo de Cartagena. Según precisa la Decisión, "Perú no participará en la adopción de decisiones relativas a la armonización de políticas macroeconómicas, a la definición del arancel externo común, al perfeccionamiento de la zona libre de comercio andino ni a las negociaciones comerciales que los restantes países adelanten a terceros"; en consecuencia, "las decisiones que se adopten en tales materias no serán de aplicación para Perú, que mantendrá una condición equivalente a la de observador en las reuniones de la Comisión...”. No obstante, Perú “... podrá celebrar acuerdos comerciales con cualquiera de sus socios andinos con el fin de mantener las corrientes de comercio establecidas". Véase Informativo Andino. $\mathrm{N}^{\circ} 1$, septiembre,1989, op. Cit., p. 3.

46 Véase al respecto Arnaud, Vicente. (1996). Mercosur, Unión Europea y NAFTA y los procesos de integración regional. Argentina, Editorial Aboledo-Perrot.

47 Mercosur nace en 1991 con el objetivo de crear un mercado común regional entre estos países y liberar los bienes y servicios a partir del año de 1995. Asimismo, se ha previsto la negociación de aranceles externos comunes que puedan asegurar la competitividad externa. El Tratado lo firman los presidentes de Argentina, Brasil, Paraguay y Uruguay. Previamente, en 1986, Argentina y Brasil firmaron los protocolos de un acuerdo de cooperación al que se incorporó Uruguay en 1988. Ver: Vacchino, J.M. (1988). "La integración Argentino-Brasileña y las relaciones entre América Latina y Europa. Reflexiones complementarias”. En: Revista Síntesis. N4, p. 299; (1989). América Latina y Europa Occidental en el Umbral del siglo XXI. Santiago, editorial, pp.1-33. 
cuatro países, así como la complementación económico-comercial, el mejor aprovechamiento de los recursos disponibles, la preservación del medio ambiente, la convergencia de los diferentes sectores de la economía y la coordinación de las políticas macroeconómicas $^{48}$, entre otras cosas.

Dada la informalidad institucional, el mecanismo es bastante amplio y puede ir variando con el tiempo; sin embargo, podemos señalar que el Mercosur se propuso culminar el proceso de formación de su zona de libre comercio en 1995 “... para lo cual viene realizando rebajas arancelarias progresivas, lineales y automáticas, acompañadas de la eliminación de restricciones al comercio entre los países miembros ${ }^{49}$ ". Asimismo, se plantea el establecimiento de un sistema de solución de controversias y posibles cláusulas de salvaguardia para el periodo de transición, máximo hasta 1994, donde se formula para este periodo un programa de liberación comercial, en forma lineal, progresiva y automática. Se van eliminando así restricciones no arancelarias o medidas de efectos equivalentes, que concluirán el 31 de diciembre de 1994, con la zona de libre comercio. Existe una desgravación escalonada para Paraguay y Uruguay en el programa de liberación para este periodo de transición.

Así, el objetivo del tratado -un espacio económico común- se configuraría para mediados de 1999, "... con una semejanza o compatibilidad de políticas macro y microeconómicas, mientras que a principios del próximo siglo se conformaría como un mercado común, con el correspondiente arancel externo común y la armonización de otras políticas pertinentes ${ }^{50}$ ".

Es de resaltar también, en este esquema de integración, que los Estados miembros se comprometen a preservar los compromisos asumidos hasta la fecha, incluido los de ALADI. Asimismo, el tratado está abierto a la adhesión de cualquier país miembro de una asociación subregional, cuya solicitud podrá ser considerada después de cinco años de vigencia del mismo.

e. Unión de Naciones Sudamericanas (Unasur). Con 388 millones de habitantes, se asienta en los dos sistemas subregionales (CAN y Mercosur), incluyendo la participación de Chile, Venezuela, Surinam y Guyana. Suman las experiencias y el acervo comunitario latinoamericano y se orienta bajo el paradigma de la Unión Europea. En abril de 1998 se firmó un acuerdo-marco para la creación de una zona de libre comercio entre el CAN y Mercosur. Así surge sobre la base de estos acuerdos de integración y se plantea un desafío fundamental que es el consenso y la participación en la cooperación económica y comercial. Unasur dio un importante paso en el fortalecimiento de este mecanismo de integración, otros dicen como el último intento de las doce naciones (Venezuela está supeditado a su ratificación como miembro pleno) de América del Sur para ingresar a las nuevas relaciones multipolar del siglo XXI. El Tratado se firmó el 23 de mayo del 2008 en Brasilia, cuya población conjunta de más de 400 millones de habitantes representa el $68 \%$ de la población de América Latina. Como proyecto de integración regional tienen como objetivo construir un espacio de integración cultural, social, económica, jurídica y política. Decimos política porque es más que integración, es un mecanismo de diálogo y concertación política; actualmente tiene el estatus de observador en la Asamblea General de las Naciones Unidas.

Los países latinoamericanos, en este marco económico, comercial y jurídico, tienen que alcanzar mayores escalas productivas, asociándose cada vez más a estos procesos de integración.

En resumen, podemos decir que el Grupo Andino, los cinco centroamericanos del MCCA, los cuatro países del Mercosur, y los quince del Caricom, se plantean como objetivo la conformación de un mercado común, utilizando los mismos instrumentos de integración; es decir, la desgravación automática, la tarifa externa común y la armonización de políticas. Casi la totalidad de los países del continente se están agrupando en mercados comunes subregionales: México se integrará al Mercado de Libre Comercio de América del Norte, integrado por Colombia, México, Venezuela. En el caso de México y Chile se plantean mediante acuerdos bilaterales cronogramas

48 Véase Instituto Boliviano de Comercio Exterior. (1991). Mercosur versus Grupo Andino. Santa Cruz de la Sierra, IBCE, junio de 1991 , p. 3. 49 Ibíd., p. 1.

50 Para un análisis minucioso revisar Cepal (1992). Tratado de Asunción del Mercado Común del Cono Sur (Mercosur): algunas consideraciones. Santiago de Chile, Cepal, Doc. LC/R. 1118, de 15 enero de 1992, p. 7 y ss. 
de desgravación amplia y total. Actualmente, Chile se mantiene al margen de estos procesos de integración y solo tiene la condición de asociado u observador.

Hoy, nos preguntamos si será posible que estos bloques de integración en el continente latinoamericano puedan llegar a establecer no solo una unión aduanera en camino a un mercado común a mediano plazo. La respuesta es que no tienen otra opción como bloque económico, pues solo de esa manera podrán consolidar su posición dentro del comercio mundial. América Latina, de hecho, subsiste a la institucionalización del diálogo y la integración económica a pesar de sus propios problemas de cada país.

El fortalecimiento de estas relaciones interregionales constituyó una prioridad más importante en América Latina. No obstante, la situación de la crisis internacional, deuda externa, la estabilidad de los procesos de democratización endebles y los problemas que existen en muchos de los países de la región, no ha dejado mucho margen para una acción externa ni a corto ni a largo plazo, ni ha ofrecido atracciones para posibles interlocutores externos. Sumando a esto, la falta de una voz unificada que les represente y que en parte testifique la diversidad de posiciones que existen en la región explica, a su vez, la existencia de varios mecanismos respecto al dialogo y la concertación política, así como a la integración económica Latinoamericana; de esta manera, se divide América Latina y -en consecuencia- se pierde poder de negociación.

América Latina tiene el triste récord de ser la región más desigual del mundo, donde la pobreza y la desigualdad todavía siguen siendo los mayores desafíos y que hoy se está tratando de reducir crecientemente. Antes en Latinoamérica, a través de su historia, existían dos tipos de sismos que se repiten: los terremotos y los golpes de estado; hoy, en cambio, en el nuevo milenio, América Latina va cambiando de rostro: nuevas ideas surgen y van quedando atrás los dogmas caducos de integracionismo de los años 60 y 70 de conceptos estatistas y proteccionistas, y en la actualidad se direcciona hacia una visión más democrática y competitiva, más desarrollada y menos pobre y dependiente desde el Sur de Río Grande hasta Tierra del Fuego. América Latina debe seguir en la construcción de su unidad política, tratando de superar sus problemas internos de cada país, donde los organismos regionales sean los espacios naturales de resolución de sus diferencias.

\section{CONCLUSIONES}

1. El surgimiento de este sistema global, sustentado en bloques regionales, llevaría a un reforzamiento y en otros, al inicio de nuevos procesos de integración.

2. La actual crisis internacional que marcó el último decenio, condujo a los países en desarrollo a buscar nuevas vías en el marco institucional internacional para un desarrollo más humano, a fin de resolver las necesidades básicas de toda su población.

3. La integración regional como mecanismo para acelerar el desarrollo económico de los países en desarrollo en pequeños mercados internos, basada en la producción, permitiría a estos países aumentar su capacidad de negociar con los países desarrollados. En ese sentido, a partir de los años 90, la gran mayoría de los países en desarrollo sigue haciendo cada vez mayores esfuerzos para integrarse en una economía mundial crecientemente competitiva. América Latina cambia de estrategia: abandona el proteccionismo y se convierte en uno de los abanderados de la liberalización del comercio.

4. Hoy en día, los problemas del subdesarrollo llevan a analizar nuevas formas de respuesta y a proponer nuevas relaciones en el comercio internacional, tanto en los diferentes organismos internacionales como en los regionales. De esta manera, se podrían considerar mejor las decisiones en las relaciones norte-sur. Es necesario un nuevo enfoque y mejores condiciones en un nuevo marco jurídico internacional para tratar estos problemas.

5. Como consecuencia de la globalización y las nuevas relaciones internacionales se constata la pérdida de influencia de los países en desarrollo en la economía mundial, que tienden a agruparse en diferentes organismos de integración económica, para así evitar ser marginados por los grandes centros de transformación. Para afrontar estos problemas en el ámbito del comercio internacional, Latinoamérica busca una mayor participación; es decir, necesita desarrollar su comercio e inversión, y luchar contra el proteccionismo para impulsar su crecimiento y así disminuir esa relación asimétrica con los centros de poder económicos internacionales. Para conseguir estos objetivos, es esencial la unidad y tener 
un interlocutor válido en las relaciones internacionales; sin embargo, es harto conocida la heterogeneidad de los países latinoamericanos.

6. En la actualidad, pese a que existe una desigual estructura económica así como una orientación distinta de las políticas de los Estados latinoamericanos, subyacen dificultades para concordar los criterios económicos en la integración. Sin embargo, se muestran considerables logros en este ámbito, ya sea a escala subregional o regional. La integración y el desarrollo económico social son un hecho irreversible en América Latina.

7. El reto de la integración en el comercio mundial en ésta década dependerá mucho del fortalecimiento y dinámica de los espacios económicos regionales actuales (Aladi, Grupo Andino, Caricom, Mercosur, etc.), así como de la recuperación del desarrollo de los países de la región y su comercio regional. Habría que tener más en cuenta la evolución de la Iniciativa de las Américas propuesta y los Tratados de Libre Comercio, precisando que los acuerdos multilaterales no son contraproducentes con los acuerdos bilaterales

8. Para concluir, podemos afirmar que en esta era del multilateralismo, es necesario superar algunos conceptos tradicionales como el Estado nacional y soberanía hacia bloques con espacios de integración económica y comercial dentro de la unidad geográfica e histórica de las naciones latinoamericanas y, de esa manera, pueda ser una de las formas de reencontrarse bajo un marco jurídico de integración.

\section{BIBLIOGRAFÍA}

\section{Libros}

Acuerdo de Cartagena. (1989). Cronología de la Integración Andina. Lima, Junta del Acuerdo de Cartagena.

Arnaud, Vicente. (1996). MERCOSUR, Unión Europea y NAFTA y los procesos de integración regional. Argentina, Editorial AboledoPerrot.

Balassa, B. (1961). The Theory of Economic Integration. Homewood, Illions, Richard D. Irwin, Inc.
Barbé, Esther. (1995). Relaciones Internacionales. España, Editorial Tecnos.

Bárcena, Alicia. (2012). "Crisis Internacional desacelera comercio latinoamericano". En: Revista de Mercados \& Tendencias. Edición $\mathrm{N}^{\circ} 65$.

Berrocal, L. (1980). El diálogo euro-latinoamericano, ¿más allá de un neocolonialismo larvado? Caracas, RIOE.

Carraud, M. (1980). L'intégration des pays andins. Paría, Oficina de Publicaciones, Bruselas.

Casado Raigón, J.M. (1992). "La integración económica europea”. En: La integración europea en la perspectiva del 92. I Curso de Comunidades Europeas, Colección Arco de Europa, Córdoba.

Castellanos, Luis. (1989). "Hacia una revisión de las relaciones con la Comunidad Europea". En: Nueva Sociedad. $N^{\circ} 106$, p. 124.

Cecchini, Paolo. (1994). La Unión Europea: eficacia y democracia. España, Edit. McGraw-Hill.

CECLA, Vol. II, Santiago de Chile: CEPAL, 14 de agosto de 1972.

CEPAL (1987). Relaciones económicas internacionales y de cooperación regional en América Latina y El Caribe. Santiago de Chile, CEPAL.

CEPAL (1992). Informativo Andino. $N^{\circ}$ I, septiembre de 1992.

CEPAL (1992). Tratado de Asunción del Mercado Común del Cono Sur (MERCOSUR): algunas consideraciones. Santiago, CEPAL, Doc. LC/R. 1118, de 15 enero de 1992.

CIDOB. (Año). "Organismes d'integracio a América Latina”. En: Revista CIDOB. N 40.

Comisión de las Comunidades Europeas: Comunicación de la Comisión al Consejo y al Parlamento Europeo. (1992). La política de cooperación al desarrollo en el horizonte 200 - Aplicación del Tratado de Maastricht. Bruselas, 16 de septiembre de 1992.

Comisión del Acuerdo de Cartagena. XXIV Periodo de Sesiones Extraordinarias.

Comunidad Andina. (1992). Informativo Andino. $\mathrm{N}^{\circ} 1$, septiembre de 1992.

Comunidad Andina. (1991). "La primera zona de libre comercio”. En: Revista del Grupo Andino. Octubre-diciembre de 1991. 
Comunidad Europea. (1984). "Acuerdos CEE/ ALA/88-6". En: Diario Oficial de la Comunidad Europea (DOCE). $\mathrm{N}^{\circ} \mathrm{L} 153$, del 08 de junio de 1984.

De la Iglesia J.P. (1988). "Las relaciones entre Europa de los Doce y América Latina. Un proceso de cambio acelerado". En: Pensamiento Iberoamericano. $\mathrm{N}^{\circ} 13$.

De la Serre, F. (año). Foreign Policity og the European Communities. Ciudad, editorial.

Deutsch, James. (1985). El nacionalismo y sus alternativas. Argentina, Editorial Paidós.

Deutsch, Karl. (1990). Análisis de las relaciones internacionales. Argentina, Editorial Paidós.

Díaz Muller, L. (1979). “La integración de América Latina: Un desafío permanente”. México ETM, 3.

Doc. S.N. 5329/90 (AMLAT) OR. es, Sen/JJ/am. Véase, Acuerdos CEE/ALA/88-6.

Dougherty, James. (1993). Teorías en pugna en las relaciones internacionales. Argentina, Grupo Editor Latinoamericano.

Franco Montoro, A. (1993). Perspectivas de integracao da América Latina. Sao Paulo, ILAM.

García, H. (1992). El Tratado de Asunción del Mercado Común del Cono Sur (MERCOSUR): Algunas consideraciones. Santiago, CEPAL, LC/R.118, del 15 de enero de1992.

Has, E. (1964). Beyond The Nations State: Funcionalism and International Organiztion. Palo Alto, California: Stanford University.

Iglesia, J.P. (1988). "Las relaciones entre Europa de los Doce y América Latina. Un proceso de cambio acelerado”. En: Pensamiento Iberoamericano. $\mathrm{N}^{\circ} 13$.

ILPES (1992). El vínculo Iberoamérica-Comunidad Europea. Planes, Políticas y estrategias de desarrollo, en la VIII Conferencia de Ministros y Jefes de Planificación de América Latina y El Caribe, del 22 al 26 de marzo de 1992.

Instituto Boliviano de Comercio Exterior. (1991). MERCOSUR versus Grupo Andino. Santa Cruz de la Sierra, IBCE, junio de 1991.

Juan y Peñalosa, R. (1991). "La CEE formaliza e impulsa sus relaciones con América Latina”. En: Boletín ICE, del 15 al 21 de abril de 1991.
Macridis, R. (1989). Foreign Policity in World Politics. New Jersey, Prentice Hall, Roy c. Ed.

Manfred Wilhelmy, V. W. (1988). "Las políticas latinoamericanas hacia Europa Occidental: los niveles nacional, regional y subregional". En: Síntesis. $\mathrm{N}^{\circ} 4$.

Mangas Martín, A. (1994). Tratado de la Unión Europea y tratados constitutivos de las Comunidades Europeas. Madrid, Tecnos.

Mariño, Jorge. (1999). "La Supranacionalidad en los procesos de integración regional. España, Editor Mave. En: Pérez, Rogelio. (1997). Historia de la política de la unión Europea, 1940-1995. España, Editorial Dykinson.

Meade, J. (1995). The theory of Customes Unions. Ámsterdam: North Holland Publishing Co.

Meller, P. (1992). "Ajuste y reformas económicas en América Latina: problemas y experiencias recientes". En: Pensamiento Iberoamericano. $\mathrm{N}^{\circ} 22-23$. Tomo II. Julio, 1992 - junio, 1993.

Mols, M. (1988). "ASEAN luego de la tercera reunión cumbre”. En: Estudios Internacionales. $\mathrm{N}^{\circ} 81$.

Moneta, C.: "L'integration Latinoamericaine Dans le contexte International des années 1990”. En: Problème d' Amérique Latine. $\mathrm{N}^{\circ} 7.1992$.

Moya Domínguez, M.T. (1983). "La Argentina ante el proceso de transición de la integración latinoamericana”. En: Anuario argentino de Derecho Internacional. 1983. Vol. I.

Peláez Gonzáles, M. (1984). “Otras organizaciones internacionales en América”. En: Instituciones de Derecho Internacional Público (M. Diez de Velasco). Cuarta Edición. Tomo II. Madrid, Tecnos.

Peláez Marón, J.M. (1992). "Las relaciones de la Comunidad Europea-América Latina y la búsqueda del interlocutor adecuado". En: Cuestiones actuales de derecho comunitario europeo". Córdoba, Servicio de Publicaciones de la Universidad de Córdoba.

Peñalosa, Juan. (1991). “La CEE formaliza e impulsa sus relaciones con América Latina”. Boletín ICE, del 15 al 21 de abril de 1991. 
Pérez, Rogelio. (1997). Historia de la política de la unión Europea, 1940-1995. España, Editorial Dykinson.

Unión Europea. (1990). Reglamento №3 - 749/83 de la Comisión: Commission CE conclusions de la deuxiéme commission miixte Communauté Europeenne- Accord de Carthagene et ses Pays members. Lima, 10 y 11 de diciembre de 1990, en Doc. S.N. 5329/90 (AMLAT) OR. es, Sen/JJ/am

Rosenthal, Gert. (1989). "Repensando la integración”. En: Pensamiento Iberoamericano. $\mathrm{N}^{\circ} 15$.

SELA (1979). SELA en Acción. Nㅜ․

SELA. (1986). Presente y futuro de la cooperación económica intralatinoamericana. Buenos Aires, INTAL.

Tasker, R. (1987). "Leaders turno ut to support Aquino despite risk. 18 minute de solidarity". En: Far Eastern Economic Review, 24 de diciembre de 1987.

The ASEAN Declaration, Bangkok, Tailandia, 08 de agosto de 1967.

Townsend Ezcurra, A. (1988). La Nación de las Repúblicas: proyecto latinoamericano del
Libertador. Caracas, Ed. Ministerio de Relaciones Exteriores de Venezuela.

Ugarte Vega Centeno, Máximo Alfredo. (1994). "Hacia un Nuevo orden económico mundial”. En: Cuadernos Jurídicos. $\mathrm{N}^{\circ} 15$. Barcelona, editorial Fontalba.

UNCTAD (1991). “La aceleración del proceso del desarrollo. Las políticas nacionales e internacionales y los problemas económicos en el decenio de 1990". En: Informe del Secretario General de la UNCTAD a la VII UNCTAD. 09 de agosto de 1991, pp. 8-10. $\mathrm{TD} / 354$.

Vacchino, J.M. (1988). "La integración ArgentinoBrasileña y las relaciones entre América Latina y Europa. Reflexiones complementarias”. En: Síntesis. N⒋

Vacchino, J.M. (1989). “Integración, cooperación y concertación en América Latina”. En: Documento N 4 PNUD-CEPAL (1989). América Latina y Europa Occidental en el umbral del siglo XXI. Santiago, CEPAL.

\section{Internet}

www.efta.int

http://europa.eu/about-eu/countries/index_es.htm 